\title{
The Numerical Analysis of Transmission Tower-Line System Wind-Induced Collapsed Performance
}

\author{
Zhuoqun Zhang, ${ }^{1}$ Hongnan Li, ${ }^{1}$ Gang Li, ${ }^{1}$ Wenming Wang, ${ }^{1}$ and Li Tian ${ }^{2}$ \\ ${ }^{1}$ Faculty of Infrastructure Engineering, Dalian University of Technology, Dalian, Liaoning 116024, China \\ ${ }^{2}$ School of Civil and Hydraulic Engineering, Shandong University, Jinan, Shandong 250061, China \\ Correspondence should be addressed to Zhuoqun Zhang; zhangzhuoqun_2006@163.com
}

Received 25 January 2013; Revised 18 April 2013; Accepted 8 May 2013

Academic Editor: Slim Choura

Copyright (c) 2013 Zhuoqun Zhang et al. This is an open access article distributed under the Creative Commons Attribution License, which permits unrestricted use, distribution, and reproduction in any medium, provided the original work is properly cited.

\begin{abstract}
The numerical simulation of transmission tower-line systems' progressive collapse performance is considered as a major research hotspot and significant project, due to the increasing number of wind-induced collapse accidents recently. In this study, the finite element models for single tower and transmission tower-line system were established to simulate wind-induced progressive collapse by birth-to-death element technique in ABAQUS/Explicit. The wind field, based on the Kaimal fluctuating wind power spectrum and harmonic superposition method, was constructed by MATLAB commercial software. The current research focuses on the dynamic behaviour and the mechanism of a typical transmission tower-line system progressive collapse under wind action with clear step-by-step description. The numerical simulation results demonstrated that transmission tower-line system collapse mechanism depended on the number, position and last deformation of damage elements. Since the gallop effect of conductor and ground lines were ignored in the single tower model, the transmission tower-line system model, which has higher computational precision than the single tower model, is relatively accurate and recommended strongly in the design.
\end{abstract}

\section{Introduction}

The transmission tower-line system, consisting of lattice support towers and conductor cables, is an important lifeline project as a high-voltage electric power carrier and play, an important role in the infrastructure system in many countries throughout the world $[1,2]$. Along with rapid development of the power industry and national economy, designing and constructing much taller and longer span high-voltage transmission towers is obvious current trend, which has proposed new requirements for structural engineering. This structural system has some particular characteristics, such as high-rise tower, large-span and crossing hypsography, the flexibility of entire structure increasing nonlinearly as its height, and power transmission tower coupling with transmission lines with different amplitude of dynamic properties [3]. Due to their particular structural characteristics, many transmission tower-line systems often collapse because of wind-loading effect. For example, the most severe events of transmission tower collapse were reported when seven towers fall down once under wind action in 1992 and 1993 [4]. The four transmission towers with $500 \mathrm{kV}$ were damaged in 1998. Six years later, the $3342 \mathrm{~km}$ electrical transmission system was destroyed by severe typhoon called Yunna [5]. According to statistical data, in 2005, there were eighteen $500 \mathrm{kV}$ highvoltage transmission towers and sixty $110 \mathrm{kV}$ transmission towers broken because of wind loads. Figure 1 shows the wind-induced collapse accident of the 5237 liner with $500 \mathrm{kV}$ transmission tower, and 10 transmission towers were broken once in Jiangsu, China [6]. The collapse of high-voltage transmission tower in Quanzhou had a significant influence on the power outage. In 2008, the pylon collapse accident of $110 \mathrm{kV}$ Pin-Zha Line I and Line II occurred in Yangjiang, China, as shown in Figure 2 [7]. Worldwide, hurricanes and downbursts also give rise to serious damages every year, especially in U.S. and Japan. A significant portion of the reported collapses include progressive collapse under wind loads that often leads to large economic and property losses.

Progressive collapse is one of the critical issues in civil engineering. It can be defined as a widespread propagation 


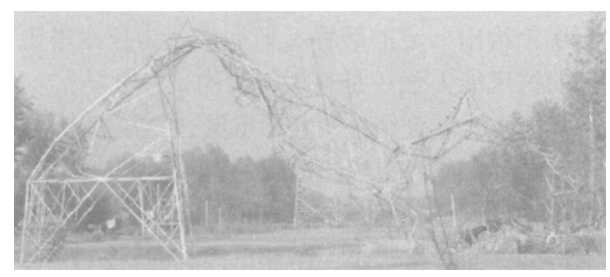

FIgURE 1: Collapsed tower in Jiangsu.

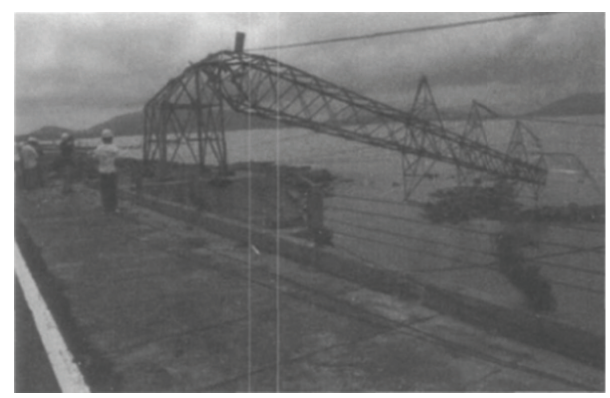

FIGURE 2: Collapsed tower in Yangjiang.

of several structural members suddenly fail in which the resulting damage is disproportionate to the original cause $[8,9]$. The attention of the engineering community was first drawn to the accident of progressive collapse following the partial collapse of a building called "Ronan Point," in London on May 16, 1968 [10], and decided on simulating, analyzing, and resisting structural progressive collapse. "Prevention of Progressive Collapse" is one of most initial comprehensive papers on the subject of progressive collapse proposed by McGuire (1974) [11]. Breen (1975) summarized the results of a workshop on progressive collapse and discussed several methods to resist progressive collapse in design which generated a number of controversial terms and debates [12]. Krauthammer (2003) discussed the limitations of using linear models to simulate the nonlinear response associated with progressive collapse and the importance of nonlinear dynamic analysis for the understanding of collapse characteristics [13]. In 2001, Lu and Jiang presented a simulation for the collapse of World Trade Center processed with the finite element software of LS-DYNA, and the parameters were discussed with real conditions [14]. The dynamic response of 2D steel-framed structures with different connection models during progressive collapse was investigated by Lim and Krauthammer (2006) [15]. Based on program of MSC.Marc finite element analysis software, a program THUFIBER for fiber model of pole system structure of ferroconcrete, was developed to simulate structure collapse by $\mathrm{Lu}$ et al. [16]. Three years later, Zhou presented a simulation and analysis on the collapse of mason building under earthquakes [17]. Lin et al. (2009) investigated and analyzed the damage mechanism of a typical RC frame in Wenchuan earthquake [18]. Lu et al. discussed the development of numerical models for earthquake-induced progressive collapse of high-rise buildings [19]. As a vital component and management in transmission tower networks, transmission tower-line system needs to assess the reliability and safety to minimise the risk of disruption to power supply that may result from in-service tower collapse or failure. However, progressive collapse analytical studies conducted by research groups in corporations or institutes evidently were not adequate and intensive, especially transmission tower-line system.

To simulate and analyze the behaviour of transmission tower-line structures during a wind-induced progressive collapse process is a complex operation with strong nonlinearity. A comprehensive study was presented in this paper to assess and understand the progressive collapse performance of transmission line structures under wind loads. The research was conducted numerically using a three-dimensional finite element model in the ABAQUS software and the simulation rule of collapse process is established based on explicit finite element method and birth-to-death element approach.

\section{Wind Load Model}

The wind flow speeds and the direction changes with time and space. As a dynamical action, the wind load is a key design load for structures, especially for high-rise and superhighrise transmission tower structures [20]. Generally, design wind loads are determined by wind tunnel tests, field measurements, or numerical simulations. Currently, numerical simulation wind is used wildly and trusted in civil engineering. Stochastic wind simulation is often divided into two parts, including stationary and nonstationary wind simulation. Both the classical linear filtration method and harmonic superposition method all belong to stationary stochastic simulation method. The nonstationary stochastic wind simulation [21-24] also can be realized by autoregressive method (AR), empirical mode decomposition method (EMD), spectral representation method (SR), Spline-interpolation-based FFT approach (SFFT), and so on. Considering transmission tower structural geometric nonlinearities, explicit finite element dynamics analysis, and simplification wind load, the turbulent wind is assumed zero-mean stationary stochastic process in this paper. Furthermore, the Kaimal fluctuating wind power spectrum and harmonic superposition method are employed by MATLAB.

2.1. Wind General Conditions. The total wind velocity in any point of a structure is the sum of the mean wind velocity and the turbulent wind velocity:

$$
v(z, t)=\bar{v}(z)+v_{f}(z, t)
$$

where $v(z, t)$ is the total wind velocity in structures, $\bar{v}(z)$ is the mean wind velocity, and $v_{f}(z, t)$ is the turbulent wind velocity.

2.1.1. Mean Wind. According to the statistic data, the mean wind is often expressed by logarithmic function or exponent function associated with the height [25]

$$
\bar{v}(z)=\frac{1}{k} u_{*} \ln \left(\frac{z}{z_{0}}\right),
$$


where $k$ is Karman constant and equal to $0.4, \bar{v}(z)$ is the mean wind speed of $z, z$ is the standard height, $z_{0}$ is the ground roughness length $(\mathrm{m})$, and $u_{*}$ is friction velocity.

2.1.2. Turbulent Wind. The fluctuating wind can be regarded as a $3 \mathrm{D}$ turbulent flow composed by the along-wind, acrosswind, and vertical-wind components. The capability characteristics of fluctuating wind range can be described by the power spectrum in various directions. According to the characteristic of transmission tower-line system, only the along-wind dynamic response is considered in this study, and the along-wind Kaimal [26] fluctuating wind power spectrum is as follows:

$$
\frac{n S(f)}{u_{*}^{2}}=\frac{200 x}{(1+50 x)^{5 / 3}},
$$

where $x=n z / \bar{v}(z)$ is the dimensionless Monin coordinate, $z$ is the height of the simulation point, $f$ is the frequency of fluctuating wind, and $u_{*}$ is the friction velocity.

2.2. Harmony Superposition Method. The harmony superposition method is a discrete numerical method to simulate the steady random process. Random signal can be decomposed into a series of sinusoidal wave with different frequency and amplitude through discrete Fourier transform. The fluctuating wind velocity time series are regarded as a random process which is determined by its power spectrum. When $N \rightarrow \infty$, with the theory presented by Shinozuka and Jan [27], the fluctuating wind velocity time series $u_{i}(t)$ is satisfied by the following:

$$
\begin{array}{r}
u_{i}(t)=\sum_{l=1}^{i} \sum_{k=1}^{N}\left|H_{i l}\left(\omega_{k}\right)\right| \sqrt{2 \Delta \omega_{k}} \cos \left[\omega_{k} t-\theta_{i l}\left(\omega_{k}\right)+\varphi_{l k}\right], \\
i=1,2, \ldots, m
\end{array}
$$

where $N$ represents the division numbers of fluctuating wind frequency, $i$ refers to the calculation point numbers, $H_{i j}$ is obtained from Cholesky decomposition of the wind crossspectral density matrix, $\theta_{i l}(\omega)$ is the argument of $H(\omega), \varphi_{l k}$ denotes the uniformly distributed random numbers in $[0$, $2 \pi$, and $\omega_{u}$ is the upper limit circle frequencies of fluctuating wind as follows:

$$
\int_{0}^{\omega_{u}} S(\omega) d \omega=(1-\varepsilon) \int_{0}^{\infty} S(\omega) d \omega
$$

$S(\omega)$ is the autopower spectrum density function, is much smaller than $1, \Delta \omega_{k}$ is frequency increment, and $\Delta \omega=$ $\left(\omega_{u}-\omega_{s}\right) / N$. To increase the period of the simulated sample, Shinozuka and Deodatis [28] suggested that

$$
\begin{aligned}
\omega_{k} & =k \Delta \omega_{k}-\frac{N-l}{N} \Delta \omega_{k} \\
& =(k-1) \Delta \omega_{k}+\frac{l}{N} \Delta \omega_{k} .
\end{aligned}
$$

Positive integer $N$ should be defined sufficiently large in order to avoid the result of distortion in (4); the number of samples in the simulated time series should be more than $2 \mathrm{~N}$, the time increment should be small enough $\left(\Delta t \leq \pi / \omega_{u}\right)$. Therefore, the time increment must be considered as follows:

$$
\Delta t=\frac{T_{0}}{M}=\frac{2 \pi}{M \Delta \omega}=\frac{2 N}{M} \cdot \frac{\pi}{\omega_{u}},
$$

where $M$ is an integer and $M>2 N$.

In conclusion, the fluctuating wind speed is a stochastic process. At this stage, time histories of the wind speed which satisfy the given power spectral densities function can be obtained. The wind speed provides that the target spectrum density function of $S^{0}(\omega)$ is designated by selecting the proper value of the $N, \omega_{u}$, and $\Delta t$

2.3. Cross-Power Spectrum. A number of observations showed that the wind field has spatial coherence which should be included in the simulation of fluctuating wind velocity on the wind turbine. In general, the simple phenomenon appeared in the natural wind field that the higher point of the structure would be attacked first and the lower point later, for the unevenness turbulence, different wind speed and phase in the different heights. Even on the same height, spatial coherence decreases as the space distance increases. $S_{i j}(\omega)$ is the cross-power spectrum which reflects the spatial coherence of fluctuating wind fields on the wind turbine and can be expressed as follows:

$$
\begin{array}{r}
S_{i j}(\omega)=\sqrt{S_{i i}(\omega) S_{j j}(\omega)} \operatorname{Coh}_{i j}(\omega) \exp [i \phi(\omega)], \\
i=1,2, \ldots, m,
\end{array}
$$

where $\operatorname{Coh}_{i j}(\omega)$ is a coherence function with characteristics of spatial coherence. Considering transmission tower-line system in this study, $\phi(\omega)$ is the length of spatial coherence between two points, which can be regarded as follows [29]:

$$
\phi(\omega)= \begin{cases}0.25 \pi f & f \leq 0.1 \\ -10 \pi f+1.25 & 0.1<f \leq 0.125 \\ \text { random } & f>0.125,\end{cases}
$$

where $f=n z / \bar{v}(z)$ is the Monin coordinate and $n$ is the frequency.

The calculation points on the tower have a vertical correlation, which is only considered in this study [30]. The fluctuating wind power spectrum can be expressed as follows:

$$
\operatorname{Coh}_{i j}(\omega)=\exp \left(-\frac{2 n C_{z}\left|z_{j}-z_{i}\right|}{\bar{U}\left(z_{i}\right)+\bar{U}\left(z_{j}\right)}\right) .
$$

The transmission tower-line system is located in flat zone in this study, so the line is considered at the same level with a smaller gap and vertical correlation in one span [31]. As a result, the mean wind and turbulent wind velocity of the 
different simulation points on line are the same, which can be expressed by the following:

$$
\begin{gathered}
S_{11}(\omega)=S_{22}(\omega)=\cdots=S_{m m}(\omega)=S(\omega), \\
S_{i j}(\omega)=\sqrt{S_{i i}(\omega) S_{j j}(\omega)} \operatorname{Coh}_{i j}(\omega) \exp [i \phi(\omega)] \\
=S(\omega) \operatorname{Coh}_{i j}(\omega) \exp [i \phi(\omega)] .
\end{gathered}
$$

\section{Collapse Simulation}

3.1. ABAQUS/Explicit. The ABAQUS/Explicit provides ABAQUS analysis technology focus on transient dynamics and quasi-static analyses using an explicit approach appropriate in those portions of the analysis where highspeed, nonlinear, and transient response dominates the solution. The ABAQUS/Explicit is considered as an explicit time integration method based on the central difference (CD) method to analyze and simulate. In order to handle effectively and accurately linear and nonlinear behaviour, the applicability of the ABAQUS/Explicit in structural dynamics is often limited by a uniform restrictively small solution time increment, without relating to load types and duration time. Each of increment steps only demands little CPU time expended. Furthermore, the lumped stiffness matrix and balance equation of structure need not to figure up by explicit finite element method. Therefore, a complex and nonlinear structural dynamics analysis can be performed effectively and successfully without a large-duration simulation $[32,33]$.

The numerical model and the boundary conditions of the transmission tower-line were constructed to simulate the progressive collapse by ABAQUS finite element software in this study. Because the wind flow speed and direction vary from time and space all the time, the system dynamic response was rapid and frequent. In order to analyze instantaneous stress and displacement of transmission structure accurately, the uniform and smaller time step for the entire mesh should be formulated to compute with the high performance, quality, and ability of the "Explicit" version of ABAQUS. Therefore, ABAQUS/Explicit was used to perform the computations to simulate the progressive collapse process by wind.

3.2. Birth-to-Death Element. In this research, the technique of element birth and death was used to simulate the progressive collapse process of transmission tower-line system. When the overloaded structural elements are caused by wind loads, these elements would be defined as failure elements and subsequently led to the progressive collapse. Because the progressive collapse of structures is initiated by the loss of one or more load-carrying members, the most important is that the loss or failure element would be simulated by the technique of element birth and death in ABAQUS. A finite element algorithm and the birth-to-death element technique were used to deal with the damage and failure evolution behavior of transmission tower members. The elements would be deleted or removed when the strain and stress increased over the critical value. Actually, the "killed" element was not removed from model [24], but the element was fabricated or deposited in a particular process step,
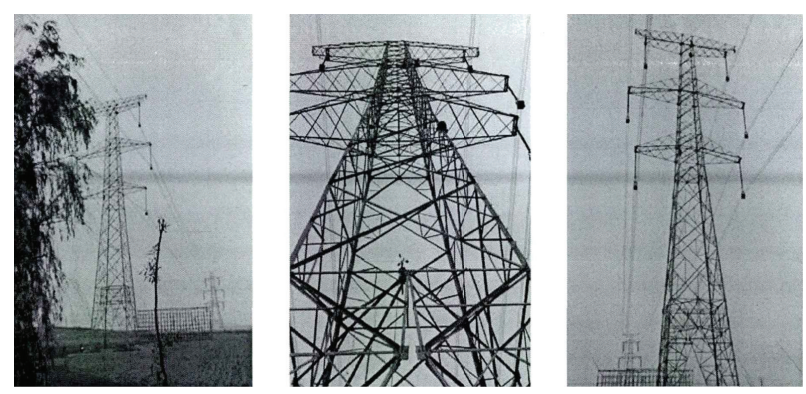

FIGURE 3: Practical graph of transmission tower-line system.

which was considered as inactive or "dead." To achieve the element "death" effect, the selected "dead elements" were deactivated by multiplying their stiffness matrices with a reduction factor, which caused the element loads associated with the deactivated elements to be zeroed out in the load vector and the element strains were also set to be zero [34]. Although the mass, specific heat, and damping of the deactivated elements were all set to zero likewise, it still appeared in element-load lists [35]. In the finite element program ABAQUS, the technique of element birth and death could be realized by writing key word. Consequently, the progressive collapse process of the transmission tower-line system under wind loads condition could be simulated in ABAQUS/Explicit.

3.3. Governing Equation of Motion. The equation of structural system under wind loads is given by finite element theory as follows:

$$
[M]\{\ddot{x}(t)\}+[C]\{\dot{x}(t)\}+[K]\{x(t)\}=\{P(t)\},
$$

where $[M],[C]$, and $[K]$ represent structural mass, damp, and rigid matrix, respectively; $\{\ddot{x}(t)\},\{\dot{x}(t)\}$, and $\{x(t)\}$ stand for acceleration response vector, velocity, and displacement in system with initial conditions; $\{P(t)\}$ is action vector on transmission tower-line system, which in this circumstance means wind loads [20].

\section{Wind-Induced Collapse Simulation}

4.1. Structural Model. A three-dimensional finite element model of the transmission tower-line system was established according to practical project $[36,37]$ in Gaizhou, China, as shown in Figure 3. A $53.9 \mathrm{~m}$ high tower was constructed with steel angle sections with $206 \mathrm{Gpa}$ elastic modulus. Its mass is 19.95 tons. The distance between adjacent towers is $400 \mathrm{~m}$. The upper 8 cables are ground lines and lower 24 cables are four-bundled conductor lines. The properties of the conductor line and ground line properties are listed in Table 1 . The power transmission tower-line system including three towers $\left(1^{\#}, 2^{\#}\right.$ and $\left.3^{\#}\right)$ and four span lines is shown in Figure 4.

4.2. Wind Simulation. Mean wind speed on $10 \mathrm{~m}$ height is assumed to be $35 \mathrm{~m} / \mathrm{s}$ in this project. The fluctuating wind 


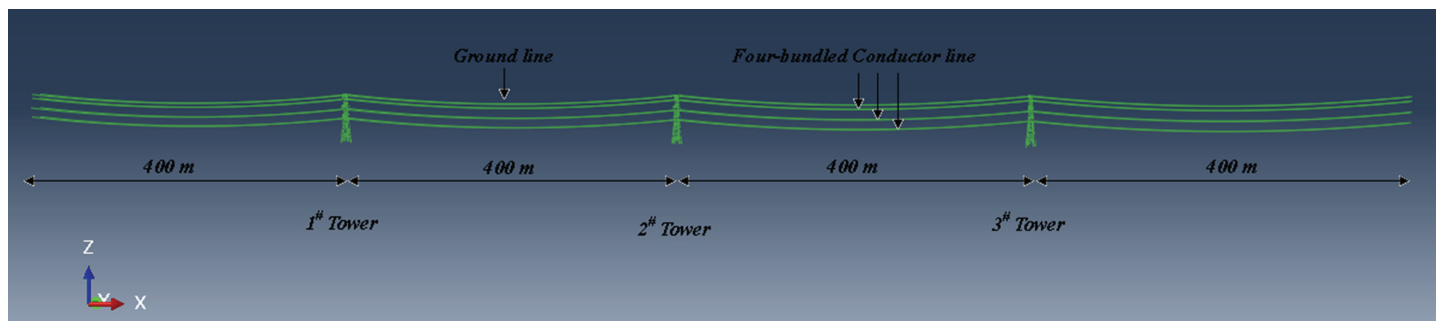

FIgURE 4: Transmission tower-line system model in ABAQUS/Explicit.

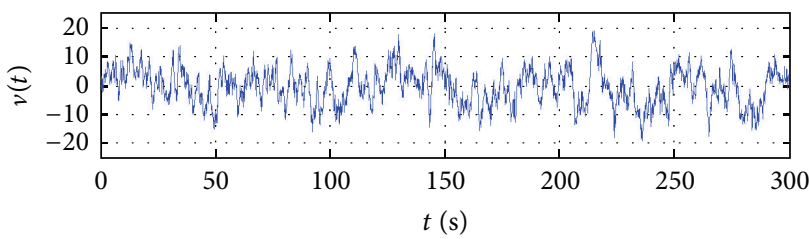

(a) Simulation point 8

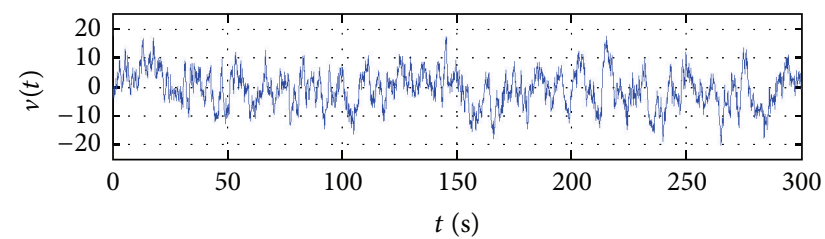

(b) Simulation point 12

FIGURE 5: The simulated fluctuating wind time history of points.

TABLE 1: Conductor line and ground line properties.

\begin{tabular}{|c|c|c|}
\hline Type & Conductor line & Ground line \\
\hline \multirow[t]{3}{*}{ Transmission line } & LGJ-400/35 & LGJ-95/55 \\
\hline & $\begin{array}{l}\text { Aluminium } \\
\text { conductor }\end{array}$ & $\begin{array}{l}\text { Aluminium } \\
\text { conductor }\end{array}$ \\
\hline & steel reinforced & steel reinforced \\
\hline Outside diameter (m) & $26.82 E-3$ & $16.00 E-3$ \\
\hline Modulus (Gpa) & 65 & 105 \\
\hline $\begin{array}{l}\text { Transversal cross-section } \\
\left(\mathrm{m}^{2}\right)\end{array}$ & $425.24 E-6$ & $152.81 E-6$ \\
\hline $\begin{array}{l}\text { Mass per unit length } \\
(\mathrm{Kg} / \mathrm{m})\end{array}$ & 1.3490 & 0.6967 \\
\hline $\begin{array}{l}\text { Line expansion coefficient } \\
\left(1 /{ }^{\circ} \mathrm{C}\right)\end{array}$ & $2.05 E-005$ & $1.55 E-005$ \\
\hline
\end{tabular}

speed simulations were conducted for 5 minutes with time intervals of $0.1 \mathrm{~s}$. In order to be more accurate, the last 100 seconds would be used to the wind velocity distribution of the SZ21 transmission tower. Because the transmission tower nodes are numerous, it is difficult to simulate the wind velocity history for every node of the tower. Simplification of the transmission tower is necessary, and in each part of the simplified region, the wind velocity of the center point is considered standard. As shown in Figure 7, the tower is divided into 15 regions. The position of load and area of wind pressure are illustrated in Table 2. Figure 5 showed a simulated fluctuating wind speed at the points 8 and 12. As illustrated in Figure 6, their power spectrum densities are described at the tower tip compared with theoretical wind samples.

The along-wind loads are calculated by the following:

$$
F(t)=\frac{\mu_{s} A V(t)^{2}}{1.6},
$$

TABLE 2: The position of load and area of wind pressure.

\begin{tabular}{lcc}
\hline Point & Height $/ \mathrm{m}$ & Area $/ \mathrm{m}^{2}$ \\
\hline 1 & 9.00 & 7.083 \\
2 & 15.0 & 4.506 \\
3 & 19.5 & 1.868 \\
4 & 24.0 & 2.435 \\
5 & 26.8 & 2.369 \\
6 & 30.0 & 2.344 \\
7 & 32.4 & 2.029 \\
8 & 35.2 & 1.672 \\
9 & 37.9 & 1.602 \\
10 & 40.6 & 1.810 \\
11 & 43.4 & 1.591 \\
12 & 46.2 & 1.117 \\
13 & 48.8 & 1.062 \\
14 & 51.4 & 1.164 \\
15 & 53.9 & 0.611 \\
\hline
\end{tabular}

where $A$ is the area acted by wind in Table 2 , and $\mu_{s}$ is shape coefficient. The shape coefficient transmission tower is equal to 2.5 based on the code. The shape coefficient of conductor line and ground line is 1.2 and 1.1, respectively. The shape coefficient of insulator is 1.0 .

4.3. Progressive Collapse Simulation. As shown in Figures 8 and 9, the single tower, three-tower and four-line finite element models were established. The structural members of towers are simulated by the B31beam elements; lines and insulators are defined as T3D2 truss elements in ABAQUS. The beam and truss elements of ABAQUS/Explicit, which could be easily implemented into existing finite element codes, are extended and applied to analyze progressive collapse. The base points of the transmission tower are fixed on the 


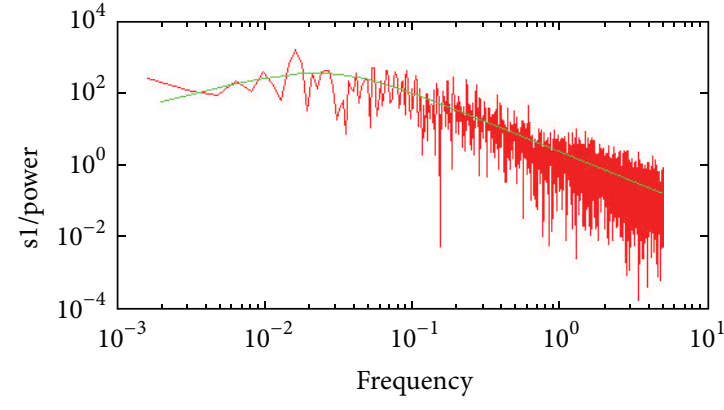

(a) Simulation point 8

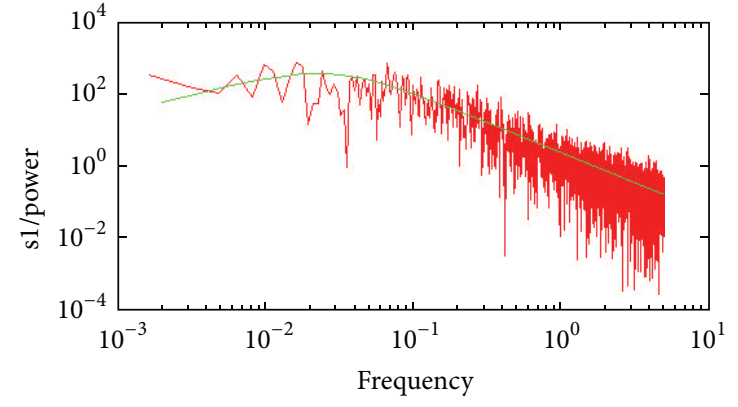

(b) Simulation point 12

Figure 6: Power spectral comparison between simulated and theoretical wind samples at points.

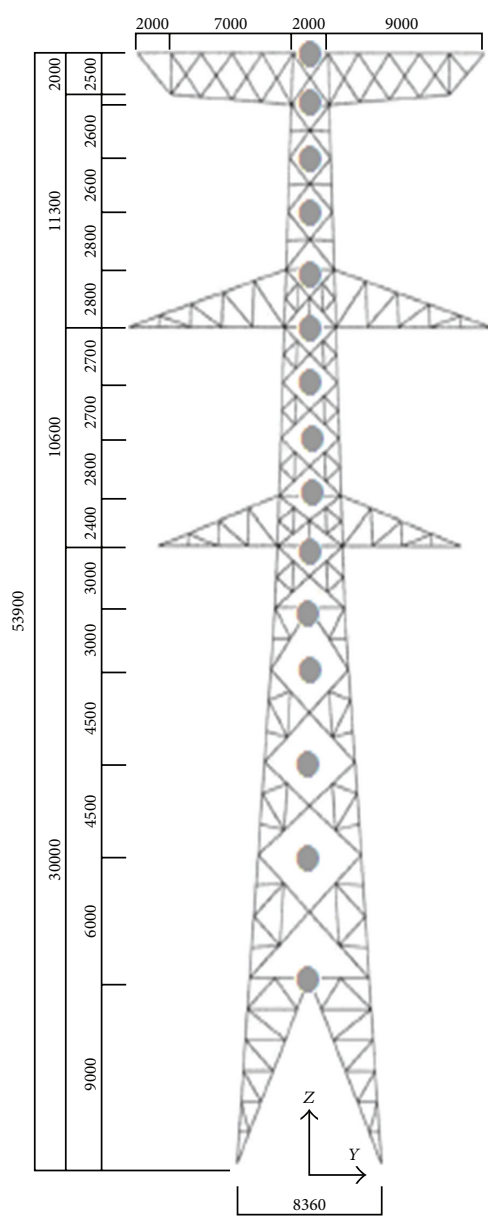

Figure 7: Wind simulation points.

ground. The connections between transmission towers and lines are hinged, and the side spans of the lines are hinged at the same height of middle tower in Figure 9. Geometric nonlinearities played a very important role in determining the progressive collapse behaviour of the transmission tower-line system in three-dimensional space. Therefore, the material nonlinearities are ignored. When the stress of steel material is larger than material yield strength, the element is considered as "deleted" in birth-to-death element technique

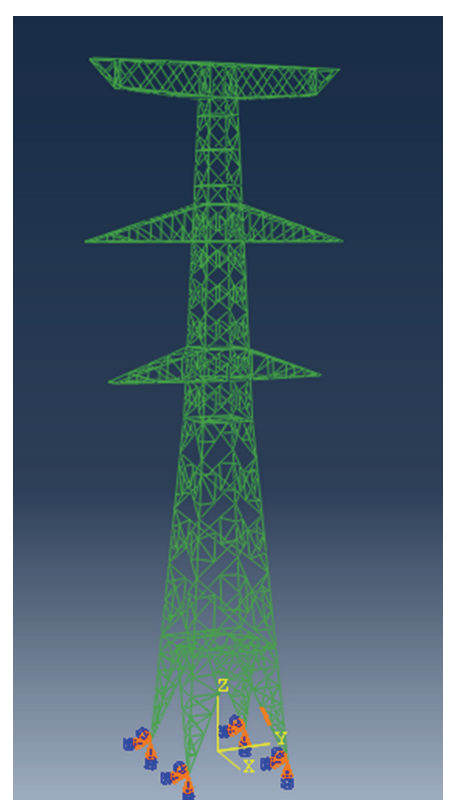

FIGURE 8: Single tower model.

in ABAQUS/Explicit. The analyses are conducted for a wind direction perpendicular to the transmission line.

4.4. Transmission Tower-Line System. Three-tower and fourline finite element models are subjected to the wind loads, which caused total progressive collapse. In several parts of the literatures, $2^{\#}$ tower is considered as the most accurate model to explain nonlinear dynamic response and progressive collapse behaviour as shown in Figures 10, 11, 12, 13, and 14. The damage element occurred on the main material of transmission tower on 15.5 second, especially the members close to the wind load point. Due to the failure of brace in portal frame, the "deleted" effect goes on from the middle to up and down. Finally, the $2^{\#}$ tower completely collapsed in several seconds. Figures 10(a), 11(a), 12(a), and 13(a) revealed the whole progressive collapse process and Figures 10(b), 11(b), 12(b), and 13(b) showed the local region of tower. Figure 14 declared the subsequent progressive collapses process of the middle tower ( $2^{\#}$ tower) from 14.65 to 15.30 seconds. More 


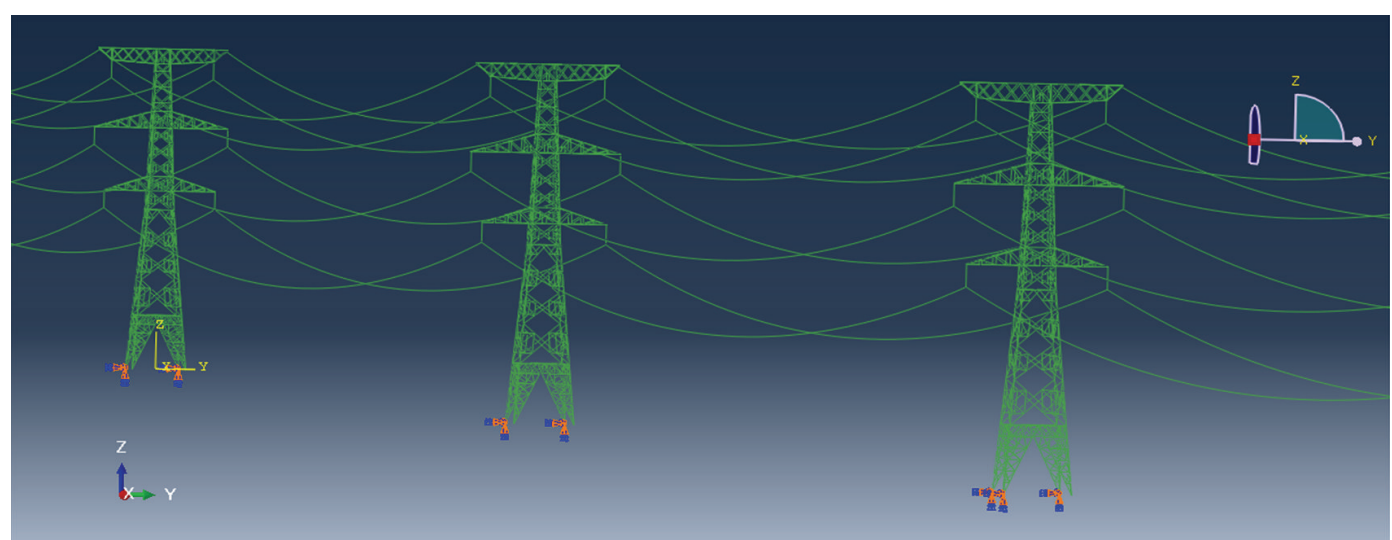

FIGURE 9: Three-tower and four-line finite element model.

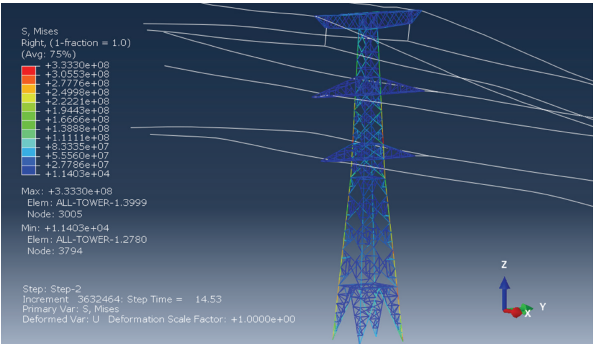

(a) $2^{\#}$ tower model

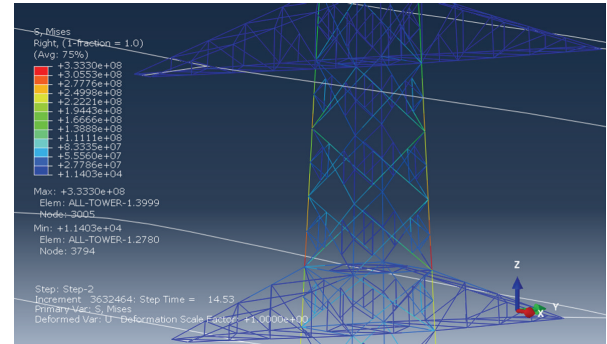

(b) Local region model

Figure 10: Wind-induced collapse of transmission tower-line system, time $=14.53 \mathrm{~s}$.

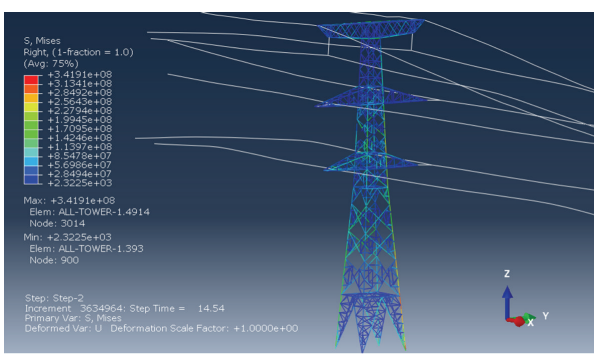

(a) $2^{\#}$ tower model

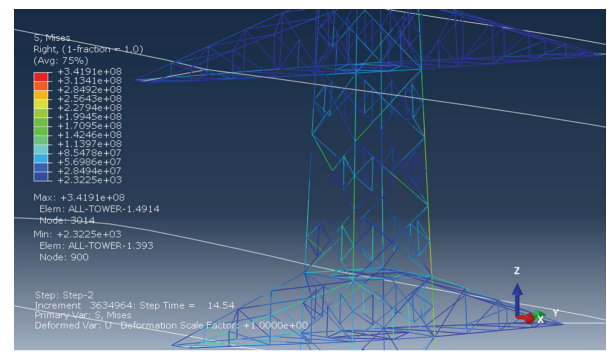

(b) Local region model

FIGURE 11: Wind-induced collapse of transmission tower-line system, time $=14.54 \mathrm{~s}$.

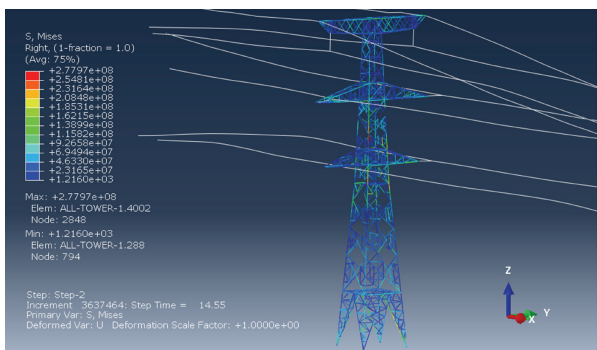

(a) $2^{\#}$ tower model

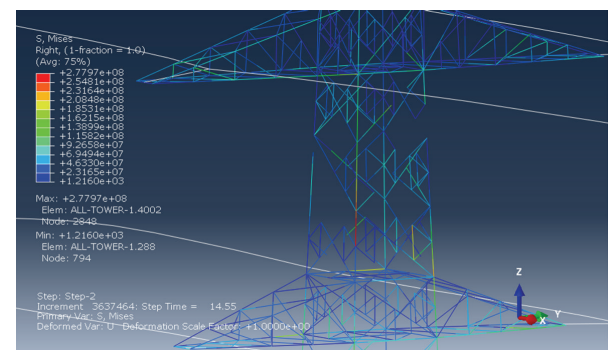

(b) Local region model

FIGURE 12: Wind-induced collapse of transmission tower-line system, time $=14.55 \mathrm{~s}$. 


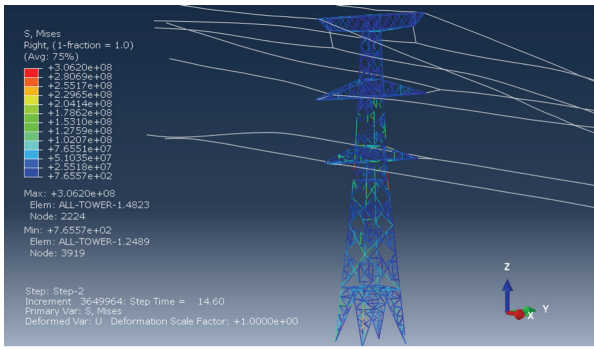

(a) $2^{\#}$ tower model

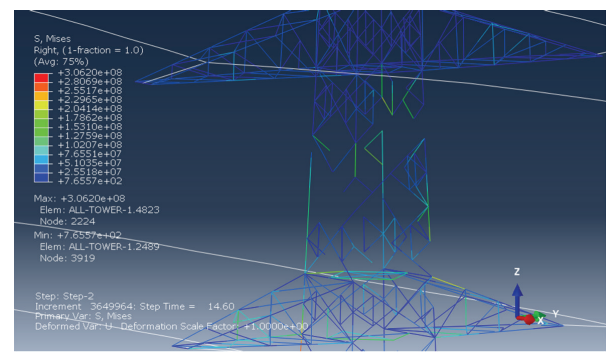

(b) Local region model

FIGURE 13: Wind-induced collapse of transmission tower-line system, time $=14.60 \mathrm{~s}$.

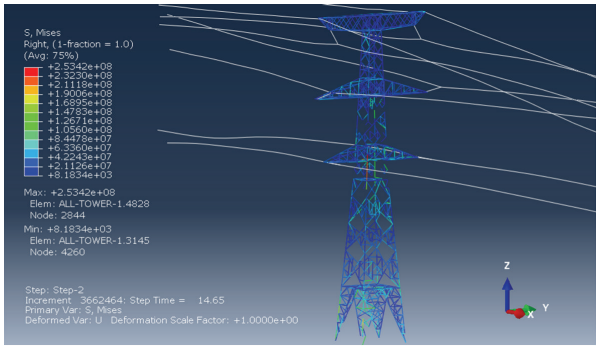

(a) Time $=14.65 \mathrm{~s}$

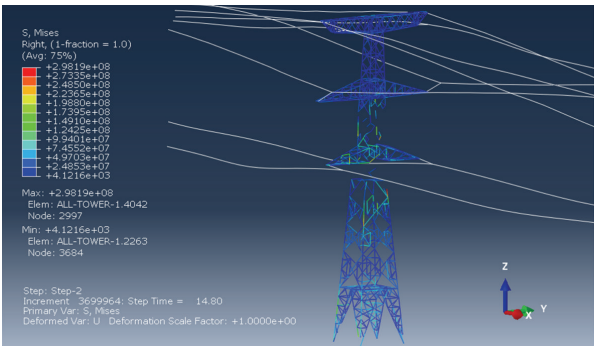

(c) Time $=14.80 \mathrm{~s}$

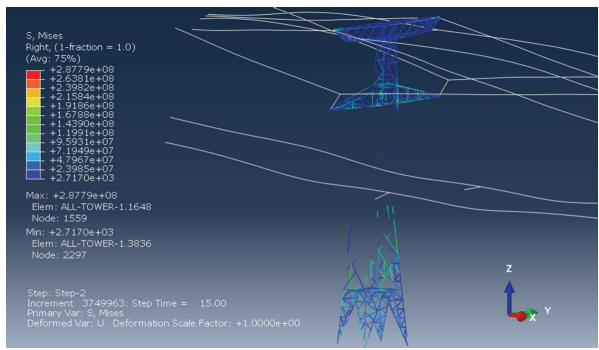

(e) Time $=15.00 \mathrm{~s}$

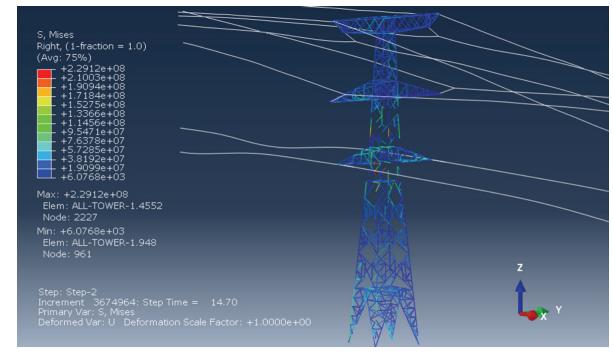

(b) Time $=14.70 \mathrm{~s}$

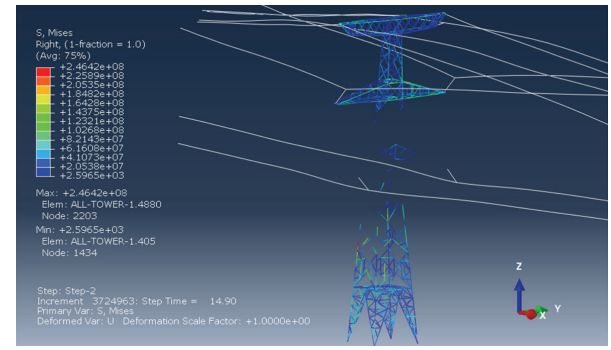

(d) Time $=14.90 \mathrm{~s}$

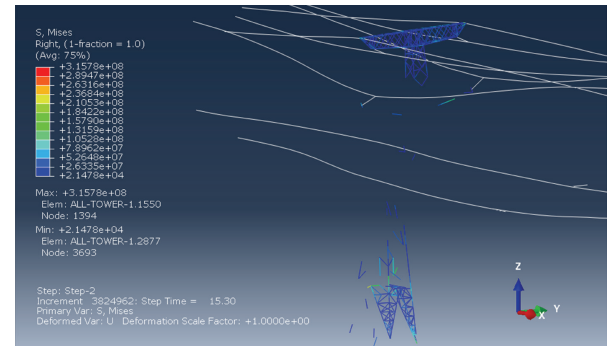

(f) Time $=15.30 \mathrm{~s}$

FIGURE 14: Wind-induced collapse of transmission tower-line system.

details about these processes are given in the following portion of this section.

Before the 14.53 second, the transmission tower-line system works well and all of elements remain elastic. Figure 11(a) showed the maximum stress of several transmission tower members reached or exceeded the material yield stress, especially on the members near the wind load point on the 14.54 second. For some tower elements satisfying "death" rule, they were "deleted," as shown in Figure 11(b), which lead to progressive collapse. That also demonstrated that the progressive collapse of structure is initiated by the loss of one or more load-carrying members. At the next instant, the dead elements lost load carrying cause further redistribution of loads and the resulting elements damage might be disproportionate in the local region near the lost member, compared with Figures 12-14, which also caused more and more elements to be failed and invalided. The order of tower element damage in progressive collapses process is illustrated in Figures 10-14. Moreover, transmission tower progressive collapse speed and path are also influenced by conductor and 


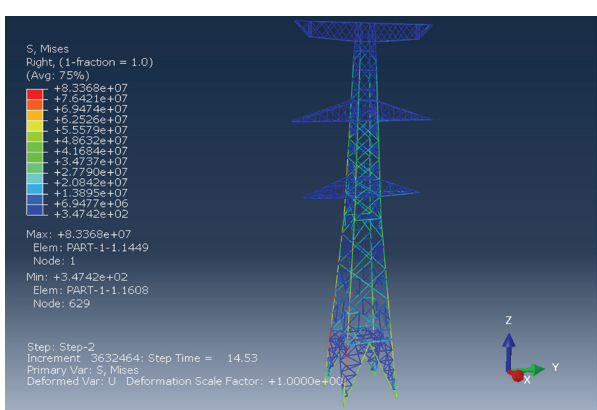

(a) Time $=14.53 \mathrm{~s}$

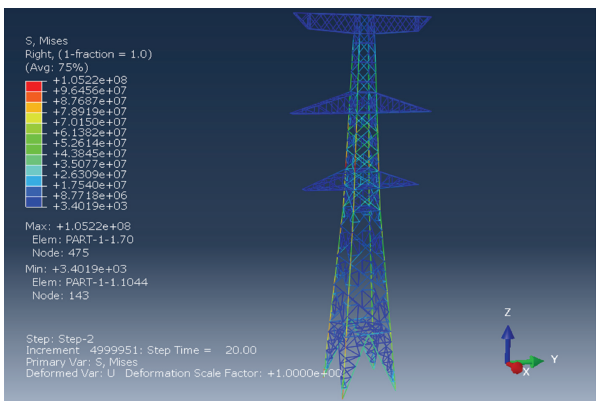

(c) Time $=20.00 \mathrm{~s}$

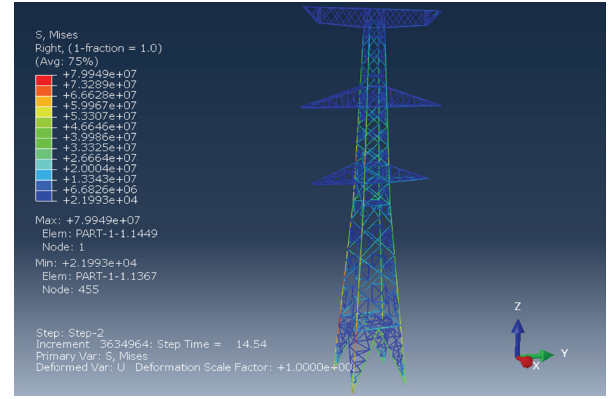

(b) Time $=14.54 \mathrm{~s}$

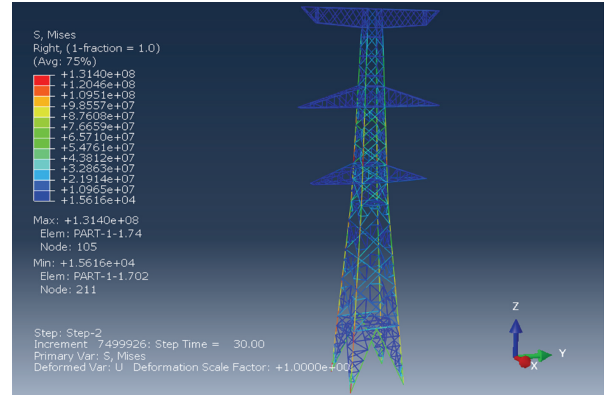

(d) Time $=30.00 \mathrm{~s}$

FIGURE 15: Wind-induced dynamic response of the single tower.

ground lines which still are kept pulling up the tower head. It was at the time 15.30 second that the transmission tower-line system was viewed as structure complete collapse.

4.5. Transmission Tower. In order to compare and illustrate, the single transmission tower $\left(2^{\#}\right.$ tower) is modeled and analyzed by birth-to-death element technique in ABAQUS/Explicit. In this case, conductor lines, ground lines and insulators were simplified to the load forces, which were applied in the model. The load condition was the uniform with tower-line system. Compared with progressive collapses of transmission tower-line system, Figures 15(a) 15(d) showed the nonlinear dynamic response of the single tower among the time $14.53 \mathrm{~s}$ to $30.00 \mathrm{~s}$. At the same time, the single tower structure did not collapse under wind load and the maximum stress of all the tower members is less than design values of material death technique. The comparison of the single transmission tower model and transmission tower-line system revealed that the conductor and ground line could appear serious gallop response in Figures 10 14 and accelerate structures collapse. Therefore, using the single transmission tower to simulate progressive collapses process by wind is inaccurate and transmission tower-line system model should be recommended.

\section{Conclusions}

A 3D-FEM model was constructed for analyzing the progressive collapses dynamic coupled behavior of a single tower and transmission tower-line system under the action of wind by the finite element software ABAQUS/Explicit. Accurate structural analysis of power transmission structures is complicated and close to the real application, which meant that the current computer simulation technique is effective for predicting and evaluating the ultimate structural progressive collapse behavior. The conclusions are as follows.

(1) A nonlinear response analysis associated with windinduced progressive collapse process of transmission tower-line system by the birth-to-death element technique in ABAQUS/Explicit is carried out. The simulation technique is important for analysis of transmission tower-line system dynamical behavior and advances the structural ability in resisting progressive collapse.

(2) When the maximum stress value of the tower element exceeds the death technique design value, the progressive collapse along with the direction of the last instantaneous deformation happened quickly. The number, position, and last deformation of damage elements are responsible for the majority of transmission tower-line system progressive collapse path. Moreover, progressive collapse speed and path are also affected by conductor and ground lines.

(3) Comparing the numerical results, the three-tower and four-line finite element model is more accurate and dependable than the single tower model with the same load condition and technique for analyzing structural nonlinear dynamic and progressive collapses behavior. Ignoring conductor and ground line gallop response, the transmission tower-line system model is recommended for progressive collapses simulation and analysis. 


\section{Acknowledgments}

This work is supported by the National Natural Science Foundation of China under Grant no. 50638010 and the Fund for Creative Research Groups under Grant no. 51121005. This support is greatly appreciated.

\section{References}

[1] H. Li and H. Bai, "High-voltage transmission tower-line system subjected to disaster loads," Progress in Natural Science, vol. 16, no. 9, pp. 899-911, 2006.

[2] H. Li and H. Bai, "State-of-the-art review on studies of disaster resistance of high-voltage transmission tower-line systems," China Civil Engineering Journal, vol. 40, no. 2, pp. 39-46, 2007 (Chinese).

[3] L. Tian, H. Li, and G. Liu, "Seismic response of power transmission tower-line system subjected to spatially varying ground motions," Mathematical Problems in Engineering, vol. 2010, Article ID 587317, 20 pages, 2010.

[4] G. Tang, "The analysis about the accident probability of $500 \mathrm{kV}$ transmission tower downburst in China," Electric Power Construction, vol. 15, no. 11, pp. 18-20, 1994 (Chinese).

[5] Y. Li and H. Bai, "Research on overhead transmission line environmental load response and design theory," Electric Power Construction, vol. 29, no. 9, pp. 38-41, 2008 (Chinese).

[6] Q. Xie, Y. Zang, and J. Li, "Investigation on tower collapses of $500 \mathrm{kV}$ renshang 5237 transmission line caused by downburst," Power System Technology, vol. 30, no. 10, pp. 59-63, 2006 (Chinese).

[7] F. Zhang, W. Huang, L. Liu, and L. Fan, "Discussion on mechanism of transmission tower falling down under strong wind and reinforcement method," Guangxi Electric Power, vol. 3, no. 4, pp. 78-81, 2009.

[8] G. Kaewkulchai and E. B. Williamson, "Modeling the impact of failed members for progressive collapse analysis of frame structures," Journal of Performance of Constructed Facilities, vol. 20, no. 4, Article ID 011604QCF, pp. 375-383, 2006.

[9] O. A. Mohamed, "Progressive collapse of structures: annotated bibliography and comparison of codes and standards," Journal of Performance of Constructed Facilities, vol. 20, no. 4, Article ID 001604QCF, pp. 418-425, 2006.

[10] K. Menchel, Progressive collapse: comparison of main standards, formulation and validation of new computational procedures [Ph.D. thesis], Université Libre de Bruxelles, Brussels, Belgium, 2008.

[11] W. McGuire, "Prevention of Progressive Collapse," in Proceeding of the Regional Conference on Tall Buildings, Bangkok, Asian Institute of Technology, Bangkok, Thailand, 1974.

[12] J. Breen, Research Workshop on Progressive Collapse of Building Structures, University of Texas at Austin, National Bureau of Standards, Washington, DC, USA, 1975.

[13] T. Krauthammer, "AISC research on structural steel to resist blast and progressive collapse," in Proceedings of AISC Steel Building Symposium: Blast and Progressive Collapse Resistance, pp. 67-81, New York, NY, USA, December 2003.

[14] X. Lu and J. Jiang, "Dynamic finite element simulation for the collapse of word trade center," China Civil Engineering Journal, vol. 34, no. 6, pp. 9-10, 2001 (Chinese).

[15] J. Lim and T. Krauthammer, "Progressive collapse analyses of 2D steel-framed structures with different connection models," Engineering Journal, vol. 43, no. 3, pp. 201-215, 2006.
[16] X. Lu, Z. Miao, J. Jiang, and L. Ye, "Collapse simulation of highrise structure of concrete under the act ion of static and dynamic load," Earthquake Research in Shanxi, vol. 2, no. 3, pp. 7-18, 2006.

[17] P. Zhou, "Simulation and analysis on the collapsing of mason building in earthquake," Zhejiang Construction, vol. 26, no. 8, pp. 27-30, 2009 (Chinese).

[18] X. Lin, P. Pan, L. Ye, X. Lu, and S. Zhao, "Analysis of the damage mechanism of a typical RC frame in Wenchuan Earthquake," China Civil Engineering Journal, vol. 42, no. 5, pp. 13-20, 2009.

[19] X. Lu, X. Lin, L. Ye, Y. Li, and D. Tang, "Numerical models for earthquake induced progressive collapse of high-rise buildings," Engineering Mechanics, vol. 27, no. 11, pp. 64-70, 2010.

[20] Y. Wang, H. Li, and T. Yi, “The dynamic reliability analysis of transmission tower under the wind action during different design periods," in Proceedings of the 2nd International Forum on Advances in Structural Engineering, pp. 388-397, 2008.

[21] M. P. Mignolet and P.-T. D. Spanos, "Recursive simulation of stationary multivariate random processes. I," American Society of Mechanical Engineers, vol. 54, no. 3, pp. 674-680, 1987.

[22] Y. L. Xu and J. Chen, "Characterizing nonstationary wind speed using empirical mode decomposition," Journal of Structural Engineering, vol. 130, no. 6, pp. 912-920, 2004.

[23] L. Chen and C. W. Letchford, "Simulation of multivariate stationary Gaussian stochastic processes: hybrid spectral representation and proper orthogonal decomposition approach," Journal of Engineering Mechanics, vol. 131, no. 8, pp. 801-808, 2005.

[24] J. Li, C. Li, and S. Chen, "Spline-interpolation-based FFT approach to fast simulation of multivariate stochastic processes," Mathematical Problems in Engineering, Article ID 842183, 24 pages, 2011.

[25] X. Zhang, Handbook of Wind Load Theories and Wind-Resistant Computations for Engineering Structures, Tongji University Press, Shanghai, China, 1990 (Chinese).

[26] E. Simiu and R. H. Scanlan, Wind Effects on Structures, John Wiley and Sons, New York, NY, USA, 3rd edition, 1996.

[27] M. Shinozuka and C. M. Jan, "Digital simulation of random processes and its applications," Journal of Sound and Vibration, vol. 25, no. 1, pp. 111-128, 1972.

[28] M. Shinozuka and G. Deodatis, "Simulation of stochastic processes by spectral representation," Applied Mechanics Reviews, vol. 44, no. 4, pp. 191-204, 1991.

[29] Z. Wang, "Simulation of wind loading," Journal of Building Structures, vol. 15, no. 1, pp. 44-52, 1994 (Chinese).

[30] $\mathrm{H}$. Bai, The dynamic response of transmission tower-line system subjected to environmental loads [Ph.D. thesis], Dalian University of Technology, Dalian, China, 2007 (Chinese).

[31] H. Li and Y. Ren, "Rain-wind-induced dynamic response analysis of transmission tower-line system," in Proceedings of the 13th National Scientific Symposium on Wind Engineering of Structures, pp. 266-276, China Civil Engineering Society, Beijing, China, 2007.

[32] Dassault Systèmes Simulia Corp, "Abaqus Glossary," 2012, http://simulia.custhelp.com/cgi-bin/abaqus.cfg/php/enduser/ home.php.

[33] Y. Shi and Y. Zhou, ABAQUS Finite Element Analysis Example Explanation, China Machine Press, Beijing, China, 2006 (Chinese).

[34] R. S. Long, W. J. Liu, F. Xing, and H. B. Wang, "Numerical simulation of thermal behavior during laser metal deposition 
shaping," Transactions of Nonferrous Metals Society of China (English Edition), vol. 18, no. 3, pp. 691-699, 2008.

[35] S. Nadimi, R. J. Khoushehmehr, B. Rohani, and A. Mostafapour, "Investigation and analysis of weld induced residual stresses in two dissimilar pipes by finite element modeling," Journal of Applied Sciences, vol. 8, no. 6, pp. 1014-1020, 2008.

[36] T. Li and H. N. Li, "Parametric study of seismic response of transmission tower-line system subjected to multi-component earthquake excitations," in Proceedings of the 12th International Conference on Engineering, Science, Construction, and Operations in Challenging Environments (Earth and Space '10), pp. 2925-2932, March 2010.

[37] T. Li, L. Hongnan, and L. Guohuan, "Seismic response of power transmission tower-line system under multi-component multisupport excitations," Journal of Earthquake and Tsunami, vol. 6, no. 4, Article ID 1250025, 21 pages, 2012. 


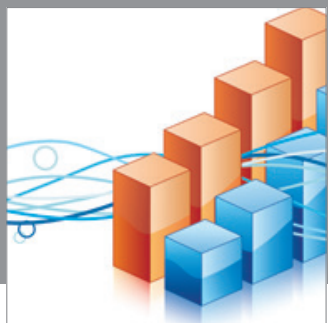

Advances in

Operations Research

mansans

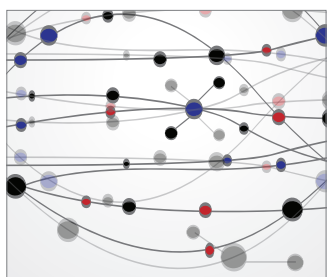

The Scientific World Journal
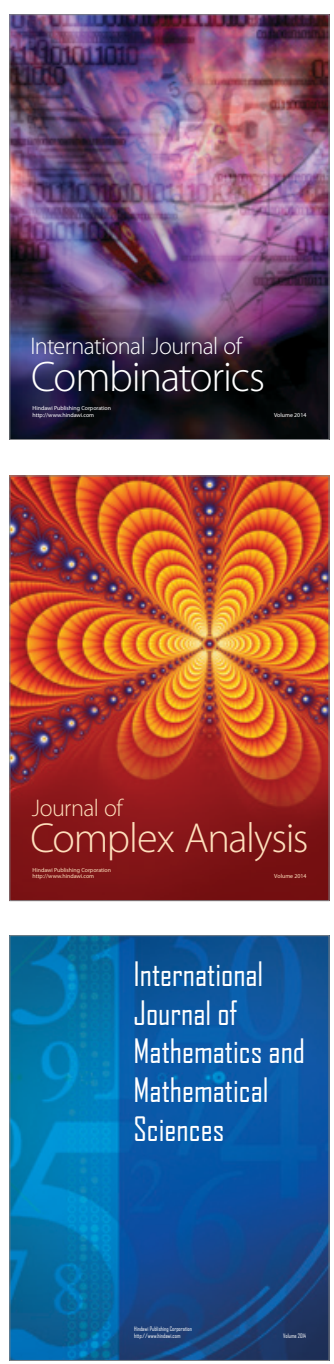
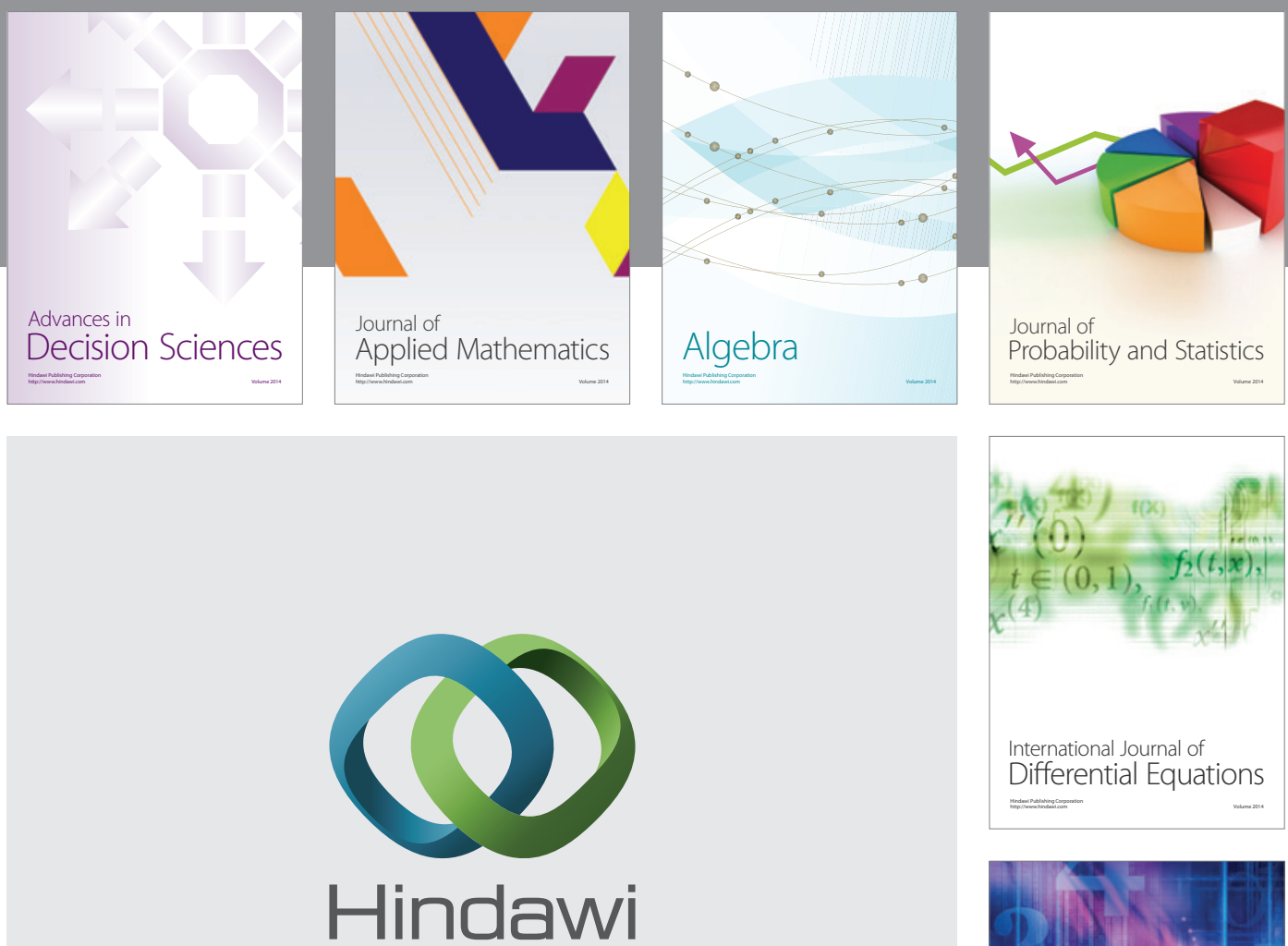

Submit your manuscripts at http://www.hindawi.com
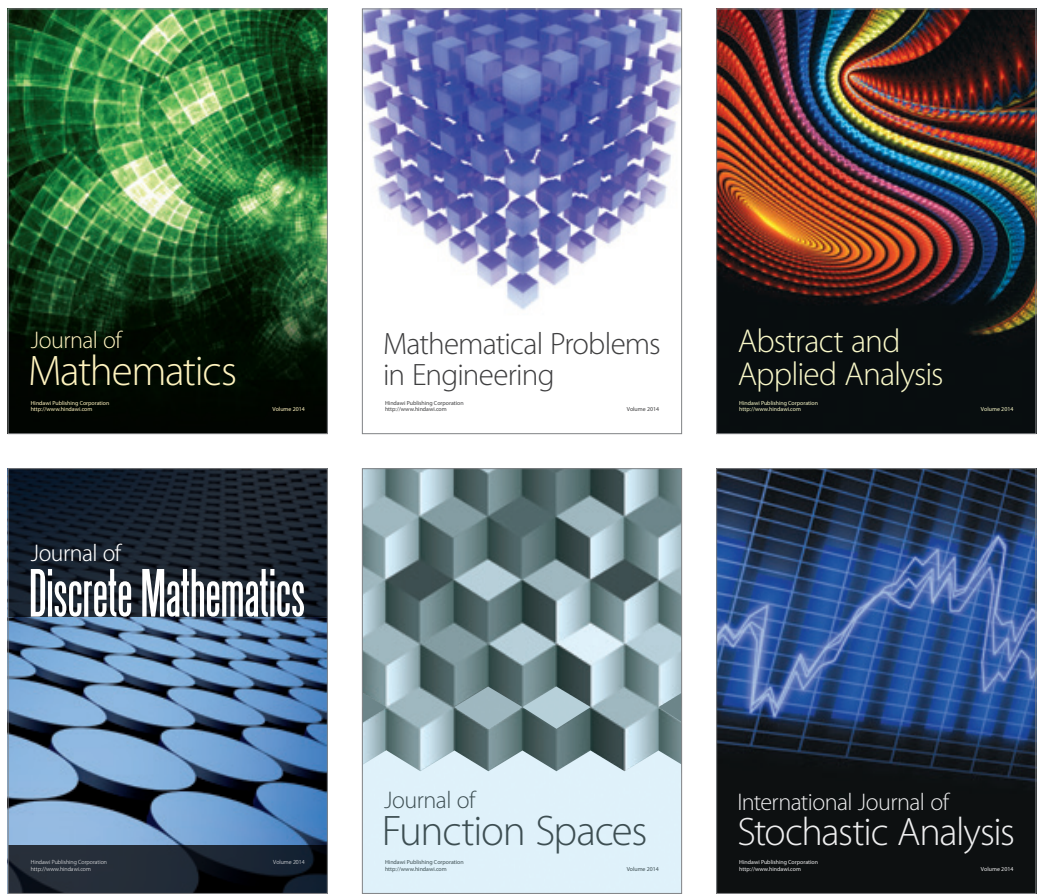

Journal of

Function Spaces

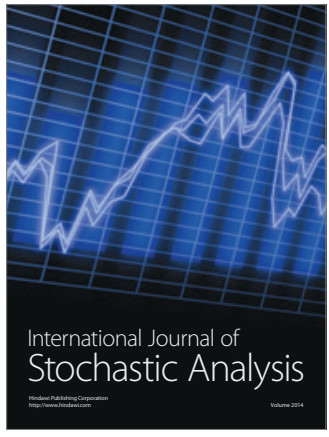

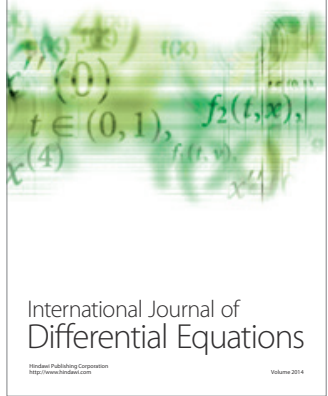
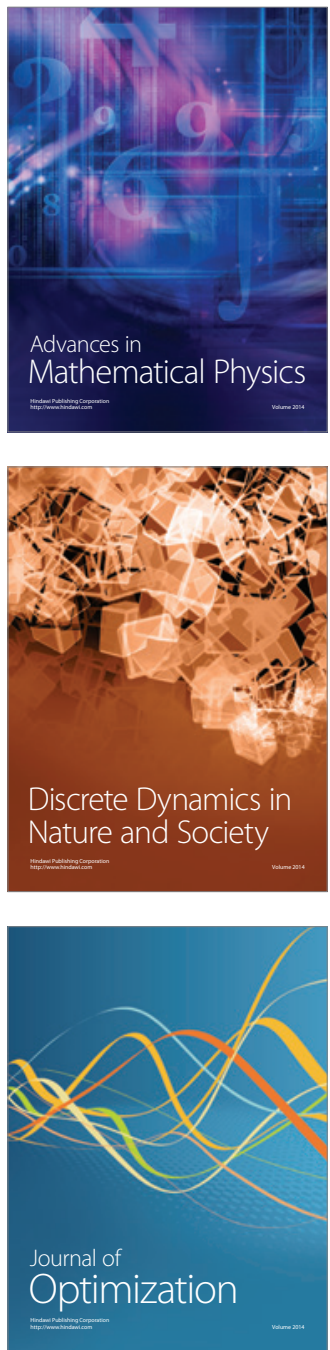